Etnográfica

Revista do Centro em Rede de Investigação em

Antropologia

vol. 17 (1) | 2013

Vol. 17 (1)

\title{
Afinal, que asilo é este que não nos protege?
}

What kind of asylum is this that doesn't protect us, after all?

\section{Maria Cristina Santinho}

\section{(2) OpenEdition \\ Journals}

\section{Edição electrónica}

URL: https://journals.openedition.org/etnografica/2522

DOI: 10.4000/etnografica.2522

ISSN: 2182-2891

\section{Editora}

Centro em Rede de Investigação em Antropologia

\section{Edição impressa}

Data de publição: 1 fevereiro 2013

Paginação: 5-29

ISSN: 0873-6561

\section{Refêrencia eletrónica}

Maria Cristina Santinho, «Afinal, que asilo é este que não nos protege?», Etnográfica [Online], vol. 17

(1) | 2013, posto online no dia 13 março 2013, consultado o 10 fevereiro 2022. URL: http://

journals.openedition.org/etnografica/2522 ; DOI: https://doi.org/10.4000/etnografica.2522

\section{(c) (i) (9)}

Etnográfica is licensed under a Creative Commons Attribution-NonCommercial 4.0 International License. 


\section{Afinal, que asilo é este que não nos protege?}

\section{Maria Cristina Santinho}

Este artigo surge na sequência da pesquisa de campo efetuada entre 2007 e 2011 , que resultou numa tese de doutoramento sobre refugiados e requerentes de asilo em Portugal. Pretende-se aqui demonstrar que existe uma significativa divergência entre o que está salvaguardado nas leis que protegem os direitos de cidadania dos refugiados e a vida de todos os dias deste "grupo" social. Salienta-se ainda que, de acordo com alguns discursos políticos e atitudes de assistencialismo social, os refugiados são percecionados, de um modo geral, como vítimas ou, pelo contrário, como oportunistas, sendo igualmente despojados do seu direito à visibilidade social e política.

PALAVRAS-CHAVE: refugiados, direitos humanos, vitimização, invisibilidade.

What kind of asylum is this that doesn't protect us, after all? - This article is based on a field research undertaken between 2007 and 2011 , which resulted in a $\mathrm{PhD}$ dissertation on refugees and asylum seekers in Portugal. Here I aim to show the significant distance between the laws that grant rights of citizenship to refugees and their daily lives. Also underlined are the two common ways in which the political discourses and social welfare perceive refugees: either as victims or opportunists, and always deprived from their right to social and political visibility.

KEYWORDS: refugees, human rights, victimization, invisibility.

SANTINHO, Maria Cristina (cristina.santinho@gmail.com) - Centro de Investigação e Estudos de Sociologia, Centro em Rede de Investigação em Antropologia, ISCTE - Instituto Universitário de Lisboa, Portugal. 


\section{INTRODUÇÃO E CONTEXTO DE PESQUISA ETNOGRÁFICA}

Os refugiados em Portugal constituem um grupo pequeno e muito diversificado, numericamente quase irrelevante, quer em termos comparativos com os imigrantes no país, quer também comparando com o número de refugiados existentes nos restantes países da União Europeia. ${ }^{1}$ A sua diversidade manifesta-se relativamente aos lugares de proveniência e aos idiomas ou pertenças religiosas, classes sociais, profissões, idades e género. Esta diversidade e o seu número inexpressivo têm contribuído para a invisibilidade do tema no contexto da sociedade portuguesa contemporânea, bem como para a ausência de debate académico e político aprofundado sobre as realidades e dificuldades quotidianas deste grupo. Nos últimos cinco anos (desde 2007), tenho vindo a realizar pesquisa sobre os refugiados em Portugal, testemunhando a luta contínua pela aceitação e integração na sociedade portuguesa, à qual estão obrigatoriamente confinados se pretendem permanecer legalmente na Europa (Santinho 2011). O início da minha investigação realizou-se no contexto do Conselho Português para os Refugiados (CPR). ${ }^{2}$ Depois, acompanhei os quotidianos difíceis de homens e mulheres, na relação com instituições como o Serviço de Estrangeiros e Fronteiras (SEF), a Segurança Social, os hospitais, centros de emprego, escolas, ou ainda nas negociações para alugar casas ou quartos. Atendendo ao número residual de refugiados, quis compreender o que justificava afinal a sua dificuldade de integração, começando por pesquisar os contornos legais que enquadram o acolhimento e a integração, em Portugal e na União Europeia. Para além de existir, no contexto nacional, uma legislação específica para refugiados (Lei de Asilo), ${ }^{3}$ e outra para imigrantes (Lei de Estrangeiros) ${ }^{4}$ constatei que, no que diz respeito à legislação portuguesa, há motivos para considerar que os direitos e deveres dos refugiados e requerentes de asilo estão devidamente salvaguardados, permitindo, teoricamente, uma boa integração, porquanto lhes é permitido trabalhar, estudar e usufruir do Serviço Nacional de Saúde nas mesmas condições da população portuguesa. Já o mesmo não se passa na maioria dos restantes países europeus. Contudo, a realidade quotidiana dos refugiados em contexto nacional é bem diferente e contraditória com o que está consagrado na lei. Partimos, pois, do princípio

I A média de pedidos de asilo em Portugal é de 150 por ano. Contudo, apenas cerca de $1 / 3$ dos que o solicitam vê o seu pedido aprovado em Portugal, pelo que os restantes ou regressam às origens ou permanecem como imigrantes indocumentados.

2 O CPR é a única ONG representante em Portugal do Alto Comissariado das Nações Unidas para os Refugiados (ACNUR). É também a única instituição responsável pelo acolhimento dos refugiados em Portugal, pelo que possui um centro de acolhimento (Centro de Acolhimento de Refugiados - CAR), situado na Bobadela, no concelho de Loures, onde os residentes podem permanecer até um período máximo de três meses. Foi neste centro que realizei boa parte da investigação.

3 Lei n. ${ }^{\circ}$ 27/2008, de 30 de junho, <www.dre.pt/pdfls/2008/06/12400/0400304018.pdf>.

4 Lei n. ${ }^{\circ}$ 23/2007, de 4 de julho, <http://dre.pt/pdfls/2007/07/12700/42904330.pdf>. 
de que Portugal está dependente das condicionantes políticas e estratégicas da gestão das fronteiras na União Europeia, determinadas mais recentemente pela agência Frontex. ${ }^{5}$ Torna-se assim necessário conhecer os debates políticos internacionais que estão por trás dum sistema comum de asilo. Não obstante, a retórica das políticas nacionais, das instituições e da própria sociedade portuguesa (que se assume tradicionalmente como um país acolhedor) está longe de encontrar o seu reflexo no espelho da realidade objetiva dos que pedem asilo por necessidade (figura 1 ).

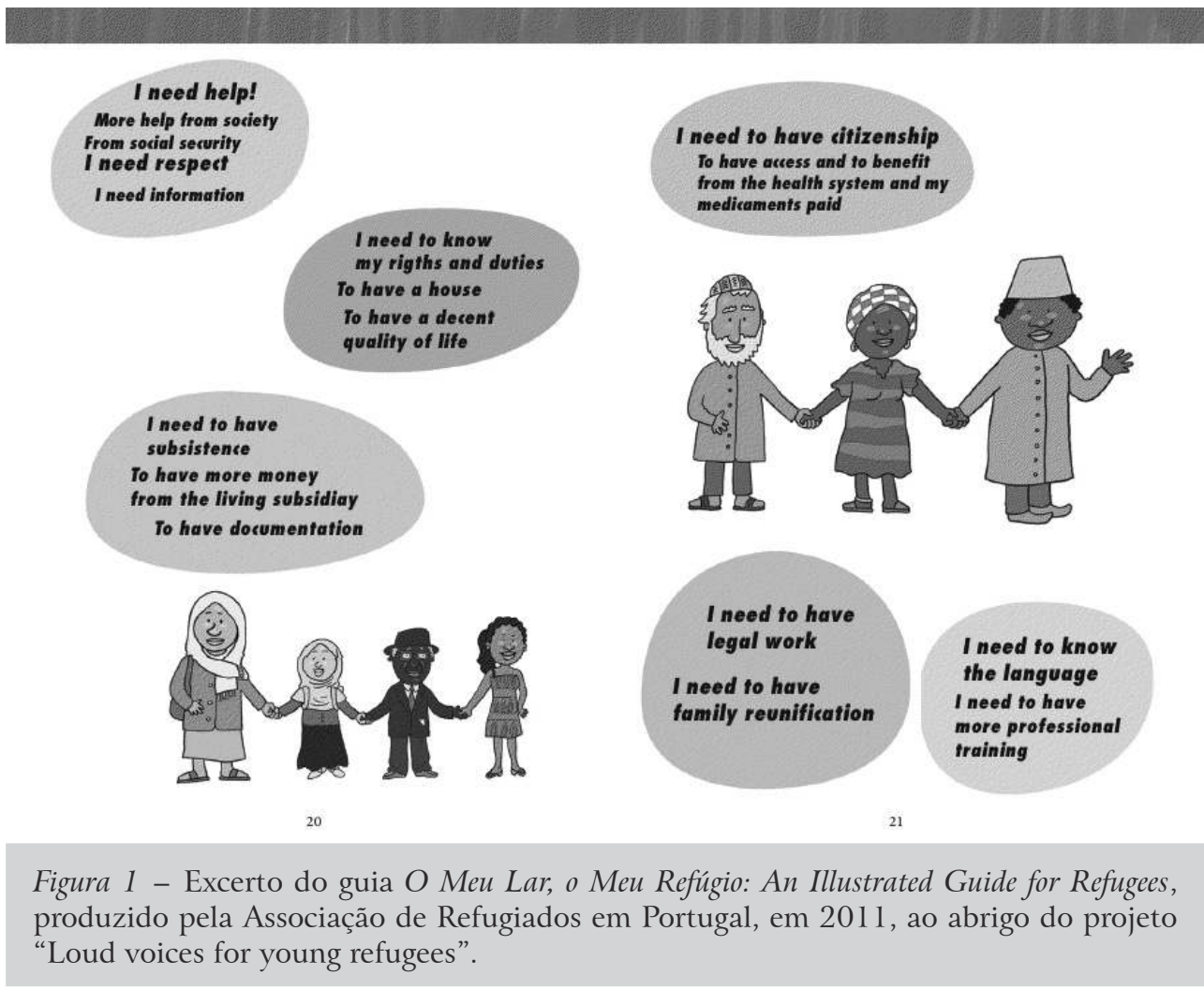

\section{EM TORNO DA NOÇÃO DE “MIGRAÇÕES FORÇADAS”}

De um modo geral, nas últimas décadas, os debates sobre imigração estão de tal modo disseminados nos contextos sociais e académicos que se torna quase redundante o aprofundamento deste conceito. Porém, proponho aqui que se desconstruam alguns significados associados a este tema, à luz das experiências 
de vida das pessoas que tiveram de partir subitamente das suas casas, deixando as famílias e o país, para fugir a perseguições políticas ou por razões económicas, mas sempre por uma questão de sobrevivência. Aqui, falamos de refugiados. Existe uma ideia mais ou menos generalizada em torno do conceito de "refugiado" e dos seus significados. Segundo a Convenção de Genebra de 1951, artigo 1. ${ }^{\circ}$ o termo "refugiado" aplica-se a qualquer pessoa que

“[...] receando com razão ser perseguida em virtude da sua raça, religião, nacionalidade, filiação em certo grupo social ou das suas opiniões políticas, se encontre fora do país de que tem a nacionalidade e não possa ou, em virtude do dito receio, não queira pedir a proteção daquele país" (ACNUR 2007 [1951]).

Um refugiado é, por conseguinte, aquele ou aquela que corre risco de vida no seu país e que pede asilo e proteção noutro país, considerado seguro (que assinou a Convenção de Genebra), alegando que não pode regressar ao local de onde partiu por estar em risco a sua própria sobrevivência (princípio de non-refoulement). ${ }^{6} \mathrm{Na}$ literatura especializada sobre a temática dos refugiados, de que são exemplo os textos do Alto Comissariado das Nações Unidas para os Refugiados (ACNUR), ${ }^{7}$ a grande diferença entre imigrante e refugiado reside no facto de, no primeiro caso, a migração não ter sido forçada, isto é, o imigrante não corre (aparentemente) perigo de vida, podendo regressar ao seu país de origem quando assim o desejar. Deliberadamente, não abordo aqui toda a problemática relacionada com os imigrantes indocumentados, ainda que ressalve a ideia - constatada na investigação etnográfica - de que tanto os imigrantes como os próprios requerentes de asilo passam frequentemente de uma situação legal para uma outra situação de "ilegalidade", por incumprimento jurídico atempado na avaliação dos processos ou por deliberações cujo fundamento não se encontra disponível para apreciação dos "leigos". ${ }^{8}$ No caso dos refugiados, aceites como tal nos postos de fronteira, os contornos são outros e bastante problemáticos. Antes da guerra ou conflito, o agora refugiado não tinha necessariamente posto a hipótese de emigrar (pelo menos não de forma urgente).

6 O princípio de non-refoulement determina que os refugiados não devem ser repatriados se no destino foram alvo de perseguição, ou se sobre eles pende a ameaça de poderem vir a sê-lo. Ver <http://www. unhcr.org/cgi-bin/texis/vtx/refworld/rwmain?docid=438c6d972>.

7 Ver: <http://www.unhcr.org/>.

8 Acompanhei pelo menos um caso de um requerente de asilo a quem, passados vários recursos, foi indeferida a autorização de permanência em Portugal como requerente de asilo. Caía sobre ele a suspeita de mentir acerca da sua origem. Ele afirmava ser do Congo, mas o SEF suspeitava que ele fosse angolano. Passou assim de requerente de asilo a imigrante ilegal, o que, a acreditar na sua versão, o remetia para o limbo dos sem terra, pois não tinha nenhum país ao qual pudesse regressar, ou onde permanecer. Até agora, o SEF não permite a consulta de processos, sendo o CPR a única entidade externa que a eles tem acesso, através do seu departamento jurídico. 
Muitos tinham inclusive uma vida próspera, do ponto de vista económico e profissional, mas, de um momento para o outro, tudo se desmoronou. Resta-lhes então fugir para outro país sem hesitar, sabendo que podem ser mortos se regressarem, enquanto as condições políticas do país de onde partiram não se modificarem. Estão, portanto, presos num tempo e num lugar determinado, sujeitos não às suas próprias decisões sobre o modo como a partir daí conduzirão as suas vidas, mas condicionados por políticas de fronteira a nível mundial ou políticas sociais a nível nacional, que irão fazer deles seres tendencialmente dependentes e passivos, durante um longo período. ${ }^{9}$

Como menciona Soguk (1999: 4), não pode existir um paradigma intrínseco associado à figura do refugiado, pronto a ser reconhecido e registado, sem que se deva tomar em consideração a sua experiência particular ou a contingência histórica. Pelo contrário, nas palavras deste autor: "Há mil experiências variadas de refugiados e mil figuras de refugiados cujos significados e identidades são negociados no processo de deslocamento no tempo e no espaço" (1999: 4). Já para Hannah Arendt (1978 [1943]), por exemplo, um refugiado é aquele que não tem um país. Assim, a cidadania deveria ser a salvaguarda dos direitos dos seres humanos, ou seja, "o direito a ter direitos". Mas, agora, chegamos a uma outra definição: "migrações forçadas". Qual o significado deste conceito ou o que significa "conceptualizar"? De acordo com o autor David Turton (2003), conceptualizar é construir algo, mais do que defini-lo ou descrevê-lo. É o resultado de uma construção mental que nem sempre encontra equivalência na vida dos atores sociais. A linguagem metafórica usada para definir o que é migração transporta consigo implicações para o modo como vemos, falamos ou atuamos sobre os migrantes. Coloca-se pois a necessidade de reflexão no uso destes termos. Esta reflexão leva-nos agora a desconstruir o termo "migrações forçadas". Só os refugiados serão migrantes forçados? E os que emigram por razões de fome e miséria, muitas vezes provocadas pela delapidação abusiva do seu ambiente ecológico? ${ }^{10} \mathrm{E}$ os que emigram por não terem assistência na doença? E os que emigram porque desejam prosseguir os seus estudos superiores e não têm condições para fazê-lo no seu próprio país? Não serão estes também "migrantes forçados"? Resta contudo um problema ético e metodológico: ao conceptualizarmos de forma diferenciada "migrantes" e "migrantes forçados" - por outras palavras, "migrantes indesejáveis", como de resto Michel Agier (2008) os denomina no seu livro Gérer les indésirables estamos a atribuir classificações hierárquicas que, na realidade, são mais complexas do que aparentemente se pode julgar. Estas classificações refletem-se,

9 É aqui que por vezes se sobrepõem as políticas internacionais e nacionais, quando, cada vez mais, as segundas dependem das primeiras. Desde 2009, a Comissão Europeia propõe a criação de uma política comum de asilo entre os diversos Estados-membros, que terá interferência nas políticas internas para esta matéria: <http://ec.europa.eu/news/justice/090218_1_pt.htm>.

10 Nestas condições estão os "refugiados do clima", por exemplo. 
por exemplo, nos diferentes estatutos jurídicos atribuídos em Portugal aos refugiados e requerentes de asilo. Boa parte dos imigrantes ou refugiados são pessoas comuns que, num determinado momento das suas vidas, se viram confrontadas com situações sociais, históricas e políticas que as fizeram mudar de vida, em direção a um outro território. Portanto, o modo como as políticas nacionais atuam sobre os migrantes depende também da forma como estes são conceptualizados.

\section{O INÍCIO DO DEBATE SOBRE UM SISTEMA COMUM DE ASILO}

Sassen (1999) refere que, no final do século XX, o mundo assistiu a uma exacerbação das tensões sociais, resultando numa crescente restrição à mobilidade humana, particularmente nos Estados Unidos e na Europa, através do uso de tecnologias de vigilância cada vez mais disseminadas e mais sofisticadas. Do ponto de vista político e ideológico, assistimos igualmente a uma crescente manipulação dos medos sociais que contribuem para diabolizar todos aqueles que são percecionados como estranhos a estes contextos. Existem razões históricas mais ou menos recentes - muro entre os Estados Unidos e o México, territórios ocupados na Palestina, em Espanha separação de Ceuta e Melila relativamente a Marrocos, para nomear alguns casos mais recentes e mediáticos - que contribuíram para uma alteração radical nos conceitos usados nas políticas de fronteira. Estas alterações estão também ancoradas em profundas mudanças económicas e políticas, nomeadamente na Europa, que, dispensando o recurso a trabalhadores imigrantes, viu generalizar-se o uso de expressões como "invasão de imigrantes", em particular por parte da imprensa sensacionalista. Quando Portugal assumiu a Presidência da União Europeia no ano 2000, para além de ter promovido um intenso debate sobre imigrações num sentido mais lato, realizou uma conferência com o título "Em Direcção a um Sistema Comum Europeu de Asilo” (SEF 2001). A organização desta conferência esteve a cargo do SEF, que possui competências para decidir sobre a aceitação dos pedidos de asilo, procedendo à instrução dos processos de concessão. ${ }^{11}$ A escolha desta temática foi determinada em particular pelos Acordos de Tempere (1999), cujo objetivo já então era o desenvolvimento de medidas com vista à criação de um sistema comum europeu de asilo, baseado numa aplicação integral e abrangente da Convenção de Genebra. Na realidade, estas medidas visaram sobretudo proteger as fronteiras comunitárias da União Europeia, através do controlo e da restrição da entrada de uma imigração já

11 “O SEF tem como missão o controlo da circulação de pessoas nas fronteiras, a entrada, permanência e atividades de estrangeiros em território nacional, prevenir e reprimir a criminalidade relacionada com a imigração ilegal e o tráfico de pessoas e a instrução dos processos de concessão dos estatutos de luso-brasileiro, de igualdade e de refugiados" (SEF 2006: 66, itálico no original). 
não desejada. ${ }^{12}$ Esta situação agravou-se um ano depois, após os atentados de 11 de setembro de 2001 nos Estados Unidos da América, com efeitos imediatos na Europa, como o "pânico moral" (Fassin 2011 ) representado pelo Islão, combinado com o "pânico político" sobre os requerentes de asilo. Fassin refere ainda: “Em ambos os casos, o 'novo mundo da migração' gerou 'novas estratégias e instrumentos de controlo' [...], por outras palavras, novo policiamento de imigrantes" (2011:216). ${ }^{13}$

Após o 11 de Setembro, generalizou-se ainda mais o princípio da desconfiança, com base na ideia de que muitos dos pedidos de asilo seriam falsos, ou seja, não teriam como justificação a necessidade de proteção motivada por perseguições e conflitos, mas sim razões económicas: a procura de melhores condições de vida. Para os requerentes de asilo, estas medidas afetaram gravemente o seu acesso aos países europeus e, na prática, tiveram como consequência a "invenção" de uma outra figura jurídica: a da "proteção subsidiária" com "autorização de residência por razões humanitárias", com o respetivo decréscimo de concessões do "estatuto de refugiado".

Da conferência atrás referida destaco o discurso do ministro da Administração Interna, à data Fernando Gomes, que sem ter em conta o número residual de requerentes de asilo em Portugal (e em geral na União Europeia, já que o maior número de refugiados se encontra nos países africanos e asiáticos e não na Europa), ${ }^{14}$ afirmou o seguinte:

"O elevado número de requerentes de asilo e pessoas deslocadas, a distinção cada vez mais impercetível entre os refugiados na aceção da Convenção de Genebra e as pessoas que, por motivo de conflitos armados, guerras civis ou graves violações dos direitos humanos, fogem dos seus países de origem, aos quais se junta ainda um elevado número de imigrantes económicos, torna cada vez mais difícil encontrar as soluções adequadas e efetivas para

12 Não desejada, no sentido em que a imigração para os países industrializados só foi estimulada no período em que se tornava necessário dar resposta a um sistema económico em expansão; ou seja, aceitou-se a mobilidade de pessoas quando existia necessidade de aumentar a produção através do aumento da força de trabalho, que escasseava na Europa. A partir do momento em que esta força de trabalho deixou de ser necessária, o sistema capitalista privilegiou a movimentação de bens e capitais, em detrimento da movimentação de pessoas. Nos dias de hoje, o significado de globalização pertence muito mais à esfera económica que à esfera social, com a consequente movimentação de pessoas: daí que o capital pretenda manter o fluxo de capitais, e não o de migrantes.

13 Algumas citações de textos noutras línguas foram livremente traduzidas para português.

14 De acordo com uma informação registada no site do CPR, no final de 2004 (ano de referência mais próximo do ano da conferência referida), o número total de refugiados e requerentes de asilo distribuía-se do seguinte modo: 3.527 .462 (36\%) na Ásia, 3.230.718 (32\%) em África, 2.337.616 (23\%) na Europa e 979.795 nos outros continentes. Estes números não incluem os refugiados palestinianos em países do Médio Oriente (4 milhões), pelo que, caso fossem considerados, o total da Europa representaria apenas 16\% (em “Dossier Fortaleza Europeia”, CPR, <http://www.refugiados. net/fort_europ/index2.html >). 
as situações, de diferente natureza, em que é exigida a concessão de proteção internacional [...]" (SEF 2001: 7).

Também o ministro do Interior da Finlândia (Kari Häkämies) assumiu num seu discurso o seguinte:

"Nestas circunstâncias, o que fazer para resolver o problema dos refugiados? Em primeiro lugar, importa naturalmente reduzir o número de refugiados, mediante a perceção e a análise das razões subjacentes ao fenómeno [...]" (SEF 2001: 16).

O que aqui se pretende destacar é a visão economicista baseada no "deve e haver" em relação a pessoas que, como sabemos, não são refugiadas porque assim o desejaram, mas porque essa é, por vezes, a única forma de sobreviver a uma guerra, conflito armado ou outro motivo que ponha em risco a sua vida. $\mathrm{Na}$ verdade, quem é que efetivamente tem em suas mãos o poder de "reduzir o número de refugiados"? A situação que gera a fuga e o consequente pedido de asilo é originada a montante e não a jusante do problema. Logo, nos países de asilo, a decisão política de redução do número de refugiados passa necessariamente por manipulações jurídicas moldadas nos contornos da lei: da atribuição do "estatuto de refugiado" passa-se a uma configuração legal mais ambígua e com menos garantias de acesso aos direitos, a dos "residentes temporários por razões humanitárias". Onde reside então a defesa dos direitos humanos, tão utilizada nos discursos políticos dos países europeus, que ao mesmo tempo se orgulham de serem espaços de "liberdade, segurança e justiça"? ${ }^{15}$ A relação entre direitos humanos e refugiados é sem dúvida uma relação íntima. Porém, os discursos proferidos a propósito são, na sua maioria, abstratos, idealistas e acríticos, em comparação com o que sucede na realidade da vida dos refugiados, tanto antes da fuga, como já depois, nos países de asilo. Como refere Balibar:

"Os direitos humanos tornaram-se, novamente, o absoluto dos discursos políticos. Mas pouco ou praticamente nada se ouve falar sobre as políticas dos direitos humanos, não há qualquer questionamento sobre as suas condições, formas e objetivos. Porquê esta discrição? Ou tal noção é considerada evidente $[\ldots]$ ou é considerada contraditória, uma vez que (ao serem o seu

15 "Libertas, Securitas, Justitia" é o lema da Frontex - a agência europeia responsável pelo sistema de controlo de fronteiras do Espaço Schengen. O seu objetivo oficial é o seguinte: "Coordenação dos serviços de informações orientada para a cooperação operacional a nível da UE para reforçar a segurança das fronteiras externas". Na definição da sua missão inclui-se ainda: "A Frontex reforça a liberdade e a segurança dos cidadãos da UE complementando os sistemas nacionais de gestão de fronteiras dos Estados-Membros" (em < http://www.frontex.europa.eu/assets/About_Frontex/Governance_ documents/Work_programme/2011/PoW_2011_PT.pdf >). 
absoluto ou o seu princípio) os direitos humanos estão sempre para lá da política ou acima dela..." (1994: 205).

Regressando à publicação Em Direcção a Um Sistema Comum Europeu de Asilo, salientamos também as palavras de Otto Schily, ministro do Interior da República Federal da Alemanha:

"Mas, quando vejo que, segundo o projeto de diretiva da Comissão relativa à proteção temporária, mais concretamente a exposição de motivos, não será possível expulsar um cidadão se no país de origem prevalecerem condições que não permitem assegurar o respeito dos direitos humanos e o Estado de direito, interrogo-me se não se tratará de uma formulação demasiado extensiva" (SEF 2001: 30).

Nestas afirmações coloca-se nitidamente a possibilidade de, nos países da União Europeia, se retirar os direitos de proteção de refugiados anteriormente expressos claramente pela Convenção de Genebra, ao sugerir que as garantias dos "direitos humanos" são demasiado abrangentes, mesmo quando se configura a hipótese de perseguição e morte. Historicamente, oscila-se entre políticas e atitudes sociais de "compaixão" e "repressão" (Fassin 2005), remetendo estas populações para novos significados associados a indivíduos com histórias liminares, numa constante procura de lugares onde se respeitem os direitos humanos, mas acusando-os também de "aproveitamento" de benesses que, aparentemente, só a Europa lhes poderia proporcionar.

Um dos discursos a destacar, por contraponto aos discursos políticos nesta conferência, é o da representante do ACNUR, Erika Feller, que evoca o autor Jeremy Arden para criticar os discursos dominantes, propondo uma outra abordagem:

"Uma conclusão que, após muita investigação, o autor considerou justificada é a de que os requerentes de asilo são cada vez menos bem-vindos em muitos países, a menos que tenham sido formalmente convidados através de programas de realojamento, ou de regimes de vistos ou de admissão temporária, vindos de países em crise. No caso de entrarem por outras vias, observa o autor, os requerentes de asilo terão de enfrentar consequências inevitáveis, entre as quais o facto de os seus motivos serem considerados de ordem económica, para além de que a entrada em situação irregular os prejudicará no processo de apreciação do seu pedido” (SEF 2001: 39).

Segundo os acordos políticos previstos nesta conferência (e aplicados posteriormente, em particular após a criação da Frontex em 2005), com vista à elaboração de um sistema comum de asilo, tendente a associar a figura do 
requerente de asilo à de imigrante ilegal, os refugiados passam a ser, a meu ver, considerados culpados até prova em contrário. Como refere o autor David Sánchez Rubio, no livro Contra Una Cultura Anestesiada de Derechos Humanos:

"Em nome de determinadas conceções dos direitos humanos, estabelecem-se condições de morte para os que não se inserem no perímetro de proteção estabelecido pelo funcionamento do sistema capitalista. A política que se utiliza é aquela que defende os direitos humanos, à custa de violar a dignidade e a vida das pessoas que não se adaptam à lógica do sistema de mercado a que estão sujeitas. [...] Basicamente, o preconceito ou o erro em que incorre o Ocidente é o de reduzir a capacidade de criar, desenvolver e desfrutar dos direitos a determinados grupos humanos, negando a possibilidade de outros grupos humanos deles desfrutarem. [...] Lutam [os imigrantes] já não apenas pela liberdade e pela igualdade, mas, principalmente, pela vida e por uma sociedade em que haja lugar para todos. Mas como põem em perigo a ordem da convivência dos países do Norte, são vistos como uma ameaça que há que controlar. [...] São tolerados unicamente os comportamentos que são afins à lógica do sistema" (2007: 81).

As políticas de fronteira no Espaço Schengen tendem, cada vez mais, a ser ditadas pelo medo e pelo controlo direcionado para aqueles que aparentemente não lhe pertencem, os quais, segundo alguns, representam uma ameaça, constituindo este um dos sentimentos mais generalizados nos discursos da maioria dos partidos de direita nos vários países da União Europeia. "Um ato de identificação implica que a coisa de que se fala seja situada numa categoria" - esta afirmação de Lévi-Strauss (1992: 21) adquire particular significado neste contexto europeu, em que o que se pretende incluir numa categoria é um sujeito que representa, na perspetiva das autoridades, uma potencial ameaça para a presumida segurança interna. Seja refugiado ou imigrante, é sempre este sujeito que passa a ser submetido a escrutínio, por não pertencer a uma cidadania nacional reconhecida, localizada e integrada nos supostos "valores ocidentais".

Este ciclo de medos acaba por gerar políticas cada vez mais restritivas face a perigos renovados, passando os imigrantes e/ou refugiados a ser filtrados pelos sistemas de controlo e retenção (centros de retenção no interior de aeroportos, e "campos" para imigrantes, onde não existe distinção entre imigrantes e requerentes de asilo, quer dentro do espaço europeu, quer, por exemplo, em Ceuta, no Norte de África). Contudo, ao erguerem-se barreiras jurídicas no espaço onde antes existiam fronteiras físicas, os Estados europeus acabam por contribuir para a proliferação de redes de traficantes ("economias paralelas" que exploram a fragilidade alheia), cada vez mais numerosas e poderosas nas fronteiras terrestres e marítimas da Europa. Bauman refere: 
"Pode atrair-se a atenção do público para os esforços de separar, entre os refugiados e as pessoas em busca de asilo, os 'autênticos' dos 'espúrios' e de identificar potenciais mafiosos e 'parasitas da proveniência' entre os que, após um exame high-tech e um meticuloso exame seletivo, já tiveram permissão de entrar no país. Para coroar tudo isto, como observou Rory Carroll, 'ao fechar virtualmente todas as formas legais de entrada, a Europa garantiu que os forasteiros não tenham escolha senão procurar o traficante. Este estabelece um preço com base na procura, no custo e no risco. A estratégia da Europa é tornar esse custo e esse risco o mais altos possível'. Novas e amplas áreas criminais são assim evocadas, proporcionando aos governos muito trabalho para proteger a ameaçada segurança dos seus cidadãos. O continuum 'migração-crime-segurança' (expressão de Goody) permite aos Estados europeus encontrarem uma nova e poderosa legitimação na nova mistura de policiamento com políticas de imigração" (2006: 119).

$\mathrm{Na}$ experiência de trabalho de campo com refugiados e requerentes de asilo não houve nenhuma entrevista ou narrativa de história de vida que não relatasse as avultadas quantias exigidas pelos traficantes de seres humanos (frequentemente donos de embarcações, camionetas ou outros meios de transporte). ${ }^{16}$ Com os sistemas securitários cada vez mais sofisticados (por exemplo, através do Eurodac $^{17}$ e da Frontex) a União Europeia acaba por, na prática, agir contra os princípios consagrados na Convenção de Genebra, sendo cada vez em maior número os refugiados que ficam ameaçados pelos próprios Estados que juraram protegê-los em vez de ficarem esses Estados ameaçados pelos refugiados.

Outra conclusão que se pode retirar é que a maioria dos Estados que assinaram a Convenção de Genebra tem uma conceção muito limitada do que

16 Dependendo do contexto territorial e/ou da capacidade negocial, estas quantias variavam entre quatro a oito mil euros, para além de existirem por vezes outros "bens" a negociar, como favores sexuais no caso das mulheres (mas não exclusivamente).

17 O sistema Eurodac permite aos Estados-membros identificar os requerentes de asilo, bem como as pessoas que foram intercetadas ao transporem ilegalmente uma fronteira externa da Comunidade. Comparando as impressões digitais, os Estados-membros podem verificar se um requerente de asilo ou um estrangeiro que se encontre ilegalmente no seu território já formulou um pedido num outro Estado-membro ou se um requerente de asilo entrou irregularmente no território da União. O Eurodac compõe-se de uma unidade central gerida pela Comissão Europeia, de uma base de dados informatizada contendo impressões digitais e meios eletrónicos de transmissão entre os Estados-membros e a base de dados central. Para além das impressões digitais, os dados transmitidos pelos Estados-membros incluem, nomeadamente, o Estado-membro de origem, o lugar e a data do pedido de asilo, se for caso disso, o sexo e um número de referência, bem como a data da recolha das impressões e a data da transmissão dos dados à unidade central. As informações são recolhidas relativamente a todas as pessoas com mais de 14 anos de idade e são introduzidas na base de dados diretamente pela unidade central (síntese online em: < http://europa.eu/legislation_summaries/justice_freedom_security/free_movement_ of_persons_asylum_immigration/133081_pt.htm >). 
implica proteger. Segundo o que aí está consagrado relativamente ao estatuto de refugiado, todos têm direito à proteção contra o refoulement, mas também devem ser-lhes garantidos outros direitos, como, por exemplo, o direito à liberdade religiosa, à justiça, à educação e à isenção de penalização por entrada ilegal, pelo facto de se encontrarem num país de asilo.

Até este momento, fez-se uma análise crítica - ainda que breve - ao modo como os direitos humanos, e em particular os direitos dos refugiados, são assumidos pelos Estados que assinaram a Convenção de Genebra. Pretendo aclarar que existe um longo e atribulado caminho que separa o que está escrito nas leis e o que é vivido quotidianamente pelos atores sociais aos quais essas leis se deveriam aplicar. Isto é, a retórica consagrada nas leis defende os Estados enquanto produtores de legislação, mas não defende necessariamente os sujeitos alvo dessa proteção.

Em Portugal, tanto no passado como no presente, os refugiados estão longe de poder usufruir do reconhecimento social que é dado aos imigrantes, no contexto da sociedade portuguesa, em parte pelo seu número irrisório face a estes, tal como referi anteriormente. ${ }^{18}$ Para que possamos entender a sua quotidianidade quase invisível, é necessário conhecer a sua expressividade numérica (quadro 1) e também estabelecer algumas comparações com países vizinhos, nomeadamente Espanha e França. Incluiu-se também a Holanda no quadro 1, para que haja uma perspetiva mais apurada de como o número de refugiados ou de pedidos de asilo está relacionado não com o tamanho do país, mas com as políticas coloniais ou pós-coloniais e também com as políticas de controlo de fronteiras na atualidade.

Quadro I

Número total de pedidos de asilo por país, 2006-2010

$\begin{array}{crrrrrr}\text { País de asilo } & 2006 & 2007 & 2008 & 2009 & 2010 & \text { Total } \\ \text { Portugal } & 130 & 220 & 160 & 140 & 160 & 810 \\ \text { Espanha } & 5.300 & 7.660 & 4.520 & 3.010 & 2.740 & 23.230 \\ \text { França } & 30.750 & 29.390 & 35.400 & 42.120 & 47.790 & 185.450 \\ \text { Holanda } & 14.470 & 7.100 & 13.400 & 14.910 & 13.330 & 63.210\end{array}$

Fonte: dados disponíveis no website do ACNUR.

18 Face aos requerentes de asilo, os refugiados são efetivamente em número muito inferior. Isto significa que a larga maioria dos requerentes de asilo só após um longo período, de em média oito anos, vê os seus direitos equiparados aos dos cidadãos nacionais, com tudo o que tal situação implica na difícil gestão da sua vida quotidiana. 
Salienta-se, de igual modo, a discrepância existente entre o número de pedidos de asilo e o número real de resoluções equivalentes à atribuição do estatuto de refugiado. Portugal é um país cada vez menos atrativo em questões de empregabilidade e condições de vida, de acordo com os requerentes de asilo entrevistados no contexto da minha investigação. Para além desta razão existem outras, das quais se destacam a quase inexistência de redes familiares e sociais de apoio que funcionem como apelo à reunificação familiar e a ausência de linhas aéreas diretas entre os países de proveniência dos requerentes de asilo e Portugal, o que dificulta a fuga por via aérea diretamente para este país.

Deve notar-se também a diversidade da origem dos que requerem asilo em Portugal. No ano de 2010 foram registados 160 pedidos de indivíduos com origens tão diversas como Somália, Sudão, Serra Leoa, Iémen, Congo, Guiné Conacri, Paquistão, Irão, Nigéria, Colômbia, Mianmar, entre outros. Apenas 21 dessas 160 pessoas provinham de países com os quais, por razões históricas, Portugal tem pontes aéreas diretas, como por exemplo Angola e Guiné-Bissau. Sublinha-se ainda que requerer asilo não significa garantir a sua obtenção. São muito raros os casos de requerentes de asilo provenientes das ex-colónias que conseguem obter com êxito o estatuto de "requerente de asilo por razões humanitárias". Coloca-se portanto a hipótese de que exista um certo evitamento, por parte do Estado português, de potenciais conflitos diplomáticos entre países com os quais Portugal tem boas relações políticas e económicas, como é o caso de Angola.

Outra questão a salientar é que a atribuição de asilo a pessoas originárias das ex-colónias portuguesas se torna mais difícil quando o pedido apresentado pelo requerente é justificado, na primeira entrevista com o SEF, com razões de perseguição devida a guerra ou conflito. Neste caso, os pedidos de asilo provenientes de Angola, por exemplo, apenas foram apresentados com mais expressão nos anos em que existia uma guerra civil naquele país (ou ainda os seus efeitos), o que justifica, por exemplo, que em 2002 tivessem requerido asilo 33 indivíduos, número que veio a decair consideravelmente nos anos posteriores. Para apurar com precisão a relação entre o pedido de asilo e a atribuição do estatuto de residente por razões humanitárias, seria necessário consultar os processos correspondentes no SEF, algo que nunca me foi permitido. Contudo, sugere-se a hipótese de que a atribuição desse estatuto de requerente de asilo (ou residente por razões humanitárias) privilegie os fatores relacionados com a situação política do país de proveniência, mais do que outros motivos também consagrados na Convenção de Genebra, como é o caso da perseguição religiosa, da filiação num grupo social, ou da "raça". 


\section{O PAPEL DA ANTROPOLOGIA NA DEFESA DOS DIREITOS HUMANOS}

A falta de informação relativa a Portugal não permitiu analisar, no transcurso da investigação, se estiveram salvaguardados os direitos dos que passam por este processo fora dos radares das ONG durante longos períodos, como por exemplo os requerentes de asilo menores, que permanecem nos centros de retenção dos aeroportos mais tempo que o legalmente previsto. As constantes violações dos direitos humanos (Farmer 2010; Green 1999; Galeano 1973; Messer 1993) não são fruto de um acidente ou de um acaso mas, pelo contrário, fazem parte dos sintomas de "patologias profundas associadas ao poder" (Farmer 2005), em relação direta com as condições sociais que determinam quem sofre abusos e quem está protegido deles. A própria Declaração dos Direitos Humanos torna-se ineficaz quando os direitos políticos e económicos das populações fragilizadas são mera retórica legislativa.

Como refere Messer (1993), a antropologia tem dado algum contributo crítico para a discussão destes temas, propiciando uma perspetiva transcultural (cross-cultural), através do questionamento sobre o que são direitos, quem é considerado "pessoa" ou "ser humano" verdadeiramente elegível para usufruir desses direitos, ou ainda sobre os abusos sucessivamente cometidos contra os mesmos. A questão dos direitos humanos tem sido ampliada através das reflexões sobre os discursos internacionais, que passaram a incluir direitos coletivos ou indígenas, com detalhes mais específicos sobre direitos económicos, sociais e culturais. Todavia, não tem sido fácil a abordagem desta temática por parte dos antropólogos. Neste campo, Farmer (2004) não os isenta de crítica, considerando-os frequentemente cegos na defesa dos direitos humanos e na interpretação daquilo que denomina "violência estrutural”. Segundo este autor, não é por se demonstrar, através de seminários e conferências, a falha no sistema que permite atentados aos direitos humanos que se altera a realidade existente. Já Michel Agier (2008) apela inclusivamente à necessidade de uma solidariedade pragmática, ou orgânica, num campo em que a investigação e o ensino são já insuficientes.

Uma das dificuldades colocadas à antropologia reside no facto de existirem, por vezes, motivos legais objetivos que impedem a investigação etnográfica no terreno político em que os direitos humanos são violados. ${ }^{19} \mathrm{~A}$ abordagem desta temática tem sido incluída num campo mais vasto da chamada engaged anthropology e da antropologia médica crítica (Scheper-Hughes 1995, 1996; Scheper-Hugues e Lock 1987), levadas a cabo principalmente através de investigações sobre temáticas como o HIV/sida, os "sem-abrigo", a pobreza e a fome, ou ainda sobre questões que envolvem imigrantes e refugiados. No caso da minha investigação, esta abordagem constituiu um desafio para a ética do trabalho

19 Referi anteriormente que o acesso aos processos jurídicos dos requerentes de asilo está vedado aos cientistas sociais ou às ONG, com exceção do CPR. 
de campo, em particular por este ter sido realizado, numa boa parte, em contexto institucional. O trabalho etnográfico está dependente (pelo menos parcialmente) da "boa vontade das instituições", existindo a possibilidade real de conflito entre o apoio (dado pela investigadora) às reivindicações pragmáticas dos grupos investigados - os utentes dessas instituições - e os contornos legais e políticos que envolvem os governos e as instituições que têm o ónus da proteção desses utentes, dentro de um determinado quadro legal. ${ }^{20}$ Coloca-se assim um dilema difícil de resolver e que circula entre escalas diferenciadas: (a) a local, que oscila entre a lógica da investigação, a lógica das instituições (CPR, hospitais, centros de saúde, centros de emprego) e a lógica dos utentes desses serviços/sujeitos de investigação; (b) a nacional, onde se incluem as instituições responsáveis pelas políticas de asilo portuguesas (por exemplo, o SEF); (c) a transnacional, através das políticas europeias de asilo (Frontex, Eurodac). Uma das formas possíveis de entendimento destas lógicas, por parte da investigação, reside na análise da retórica produzida pela legislação que assume a proteção dos grupos mais vulneráveis (neste caso, os refugiados), confrontando-a com a realidade vivida por esses mesmos grupos, em resultado das intervenções institucionais. A pesquisa etnográfica e consequente produção científica ou ainda o envolvimento militante, através da empatia com as causas defendidas por essas populações ditas vulneráveis, ou até a tradução de documentos oficiais e esclarecimento sobre o modo de funcionamento das instituições podem configurar-se como formas de intervenção ativa na defesa dos direitos de cidadania dessas populações, frequentemente dependentes e condicionadas pelas instituições totalitárias. Tal como relembram Fassin e Rechtman: "É no ponto em que a violência desaparece do nosso campo de visão que se torna crucial o trabalho da antropologia" (2009: xiii).

A este propósito saliento ainda a ausência, aquando da realização da pesquisa, de dados disponíveis para consulta (na página web do SEF) sobre as razões que levam à suspensão da autorização de residência. A relutância do SEF em prestar informações reflete-se também na relação com os que dele dependem, como se pode perceber no depoimento de um requerente de asilo, menor, entrevistado durante a realização do trabalho de campo e que demonstra, de certo modo, a desorientação por ausência de informação sobre os seus direitos, aquando da chegada ao aeroporto e após o pedido de asilo:

"Estive lá muitas semanas [no Centro de Retenção do aeroporto]. A comida era pouca e má, não dormia nada porque tinha medo que alguém chegasse e me mandasse de novo para a minha terra. Éramos quatro ou cinco no mesmo quarto, mas não falávamos a mesma língua, não nos

20 Como acontece no caso do Conselho Português para os Refugiados, que tem o encargo legal de prover ao acolhimento dos refugiados e requerentes de asilo. 
compreendíamos. Também não tínhamos janelas. Aí fizeram-me várias entrevistas. Sempre as mesmas perguntas sobre a minha família e os problemas na minha terra e como tinha chegado aqui. No dia 5 de julho de 2007 chegaram dois polícias, que disseram: 'T, você pode entrar em Portugal'. Daí pagaram-me um táxi para a Bobadela. Fiquei muito assustado porque não sabia para onde ia".

A ausência de orientações ou informação detalhada desrespeita os direitos dos requerentes e perpetua o sobressalto a que estão sujeitos e a que a fuga dos seus países deveria pôr fim. Por vezes, as políticas de asilo permitem que esse sobressalto persista mesmo depois de se ter o direito de asilo assegurado:

"Eu antes sentia-me bem, nunca tive problemas. Mas agora, sinto-me mal. O meu corpo está fraco. Não consigo dormir nem comer. Estou sempre a pensar como é que vou conseguir trabalho para mandar dinheiro para a minha família que ficou lá. Eu tinha uma boa vida até que tive que fugir para não me matarem... Ninguém me dá trabalho aqui".

A surpresa pela constatação empírica da precariedade atual das suas vidas leva-os a pôr em perspetiva o passado, o presente e até o futuro. $\mathrm{O}$ asilo, anteriormente considerado como a única solução para a recuperação da liberdade e dignidade perdidas, revela-se afinal um lugar inseguro, imprevisível e até (de novo) ameaçador. As promessas jurídicas de proteção não correspondem, de todo, à realidade quotidiana dos que vivem em situação de dependência forçada:

“O subsídio ${ }^{21}$ que me dão não dá para pagar o quarto, comer e pagar os transportes para andar à procura de trabalho. Às vezes, penso: fugi das balas, mas aqui morro todos os dias mais um bocadinho. De que me serve ter asilo se não consigo sobreviver com dignidade? Já pensei em pedir asilo numa prisão. Aí temos cama e temos comida... A liberdade não me serve de nada, se não tenho trabalho nem dinheiro para viver... Fazem de nós vítimas à força".22

\section{PARA ALÉM DA RETÓRICA JURÍDICA}

A dificuldade em entender os contornos de uma situação jurídica que passa abruptamente de "residente por razões humanitárias" para imigrante ilegal ou indocumentado agrava a permanência e dificulta a integração em Portugal dos

21 O subsídio deste refugiado é de 187 euros mensais.

22 Testemunho de um refugiado, ex-funcionário de uma organização de direitos humanos no Congo, que já havia saído do centro de acolhimento há alguns meses aquando da realização da entrevista. 
requerentes de asilo. ${ }^{23}$ Entende-se, pois, que se sintam desorientados e tenham uma perceção ambígua de um país que, num primeiro momento, os autorizou a entrar, reconhecendo-os como pessoas vítimas de perseguição e como tal protegidas pela Lei de Asilo e, num segundo momento, os trata como imigrantes ilegais, aparentemente sem direitos de cidadania. Saliente-se que a passagem de um estado para outro não depende necessariamente de qualquer infração cometida pelo requerente de asilo, mas, sobretudo, de um aparelho burocrático de avaliação de requerimentos que, por não ser capaz de analisar os processos atempadamente, empurra o requerente para um sistema de invisibilidade forçada, atribuindo-lhe um recibo provisório que atesta o pedido de renovação de documentos perante o SEF, mas que não é formalmente reconhecido pelas instituições portuguesas (pelas potenciais entidades empregadoras, por exemplo). ${ }^{24}$ A dificuldade acrescida em alugar quarto ou casa, em encontrar empregador que the autorize o trabalho formal, ou ainda a continuidade do subsídio da Segurança Social (SS) ou da Santa Casa da Misericórdia (SCM) são consequências imediatas de um estatuto indefinido socialmente, cuja única responsabilidade cabe às instituições oficiais, como o SEF.

Pela existência de um sistema informático que liga o SEF às diversas entidades, nomeadamente a SCM e a SS, assim que um requerente de asilo entra no labirinto do pedido da renovação de documentos é instantaneamente sinalizado por estas duas entidades, que suspendem de imediato o subsídio mensal vital para a sua sobrevivência:

"Fui à Santa Casa perguntar qual a razão por que este mês não recebi o subsídio. Nem me avisaram que não ia receber nada este mês. O que é que eu vou fazer? Como é que pago o meu quarto? Como é que vou pagar comida para me alimentar? A senhora da Santa Casa disse-me que o subsídio foi suspenso porque já não tenho papéis. Mas porque é que não tenho papéis? Os meus papéis acabavam em 19 de fevereiro de 2010. Eu sabia disso, por isso, a partir de novembro de 2009, comecei a ir ao SEF para pedir

23 A recusa do pedido de asilo pode ter como fundamento a desconfiança, por parte do SEF, da nacionalidade alegada pelo requerente. Um dos casos que acompanhei dizia respeito a um requerente de asilo que afirmava a sua nacionalidade congolesa, mas que, segundo o SEF, seria angolano, recusando-lhe assim o asilo. O CPR interpôs recurso junto ao tribunal. Este processo arrasta-se desde 2007 até hoje, sem que, entretanto, este requerente de asilo possa beneficiar dos subsídios que são devidos às pessoas nesta situação.

24 No artigo $78 .^{\circ}$, número 7 , da Lei n..$^{\circ}$ 23/2007, de 4 de julho - Lei de Estrangeiros -, referente à renovação da autorização de residência temporária, está escrito o seguinte: "O recibo comprovativo do pedido de renovação de autorização de residência vale como título de residência durante um prazo de 60 dias, renovável". Numa entrevista a um dos inspetores do SEF em que foi levantada a questão específica sobre a incompatibilidade entre o que está escrito no referido recibo de papel verde (30 dias) e a lei que corresponde ao direito de asilo, este admitiu que o SEF não tinha feito recibos próprios para os requerentes de asilo, razão pela que usavam os recibos aplicáveis aos imigrantes em geral. 
a renovação do documento de 'residente por razões humanitárias'. Fui lá várias vezes. Um dia lá no SEF disseram-me que não era assim, que tinha de esperar. Que eram eles que marcavam a data da entrevista para começar a renovação do documento. Ligaram-me um dia. Sabe para que data? Para 18 de fevereiro de 2010. Os meus documentos acabavam no dia seguinte! Estamos em junho e ainda não tenho os documentos renovados. Deram-me um papel verde com a validade de 30 dias, mas este papel não serve para nada. Já tinha uma promessa de trabalho, mas quando mostrei ao meu futuro patrão este documento, ele disse-me que isto não servia para nada porque não provava que eu estava legal. Se Portugal nos dá asilo, então porque é que não nos deixa integrar? Estão à espera que a gente desapareça, morra ou vá para a prisão? Afinal, que asilo é este que não nos protege nem nos deixa seguir o nosso destino neste país?"25

Através destas afirmações, podemos verificar que estamos, uma vez mais, perante uma situação em que a "assistência" jurídica e social prestada aos refugiados pelas instituições os empurra frequentemente para uma situação de exclusão e sofrimento (Kleinman, Das e Lock 1997; Bauman 2005).

A pouca expressividade numérica dos refugiados tem também consequências diretas no modo como veem a sociedade portuguesa e são vistos por ela. O facto de serem encaminhados para o Centro de Acolhimento para Refugiados (CAR ${ }^{26}$ imediatamente após o pedido de asilo dar entrada no SEF, e o facto de este centro estar localizado fora de Lisboa, numa freguesia no município de Loures (Bobadela), fazem com que os refugiados procurem casa ou quarto para alugar nas ruas adjacentes ao CAR. Esse confinamento a uma determinada área muito localizada contribui para que raramente se saiba da existência de refugiados noutros municípios ou regiões do país, e faz com que as instituições fora da região de Loures e a sociedade portuguesa, de um modo geral, apenas ouçam falar desta população nos meios de comunicação social, em notícias normalmente associadas a êxodos de zonas de conflito em países longínquos, que os retratam de um modo estereotipado. As vidas quotidianas, as dificuldades ou êxitos pessoais que vão obtendo já em território nacional ficam, contudo, fora dos radares da comunicação social e, consequentemente, da sociedade. Uma das queixas recorrentes dos refugiados nas reuniões da sua associação, recentemente formada, ${ }^{27}$ refere a revolta por os seus documentos (enquanto requerentes de asilo) não serem reconhecidos pelos técnicos da SS

25 Esta pergunta, que usei no título deste artigo, é uma das frases recorrentes pronunciadas pelos refugiados em Portugal.

26 O CAR é uma estrutura pertencente ao CPR e abriga os requerentes de asilo, em média, durante três meses após a sua chegada a Portugal.

27 Associação dos Refugiados em Portugal (ARP). 
fora de Loures ou Lisboa. Essa revolta está expressa nesta frase pronunciada regularmente: "Mas afinal quem nos deu asilo? Portugal ou Loures? Sempre que [os técnicos] olham para os nossos documentos, desconfiam de nós como se lhes estivéssemos a mentir..."

A mesma invisibilidade que os coloca à margem do sistema político e social tem um impacte particularmente significativo nas limitações de acesso ao sistema de saúde a que têm, por lei, direito. Isto é tanto mais dramático quanto o sofrimento a que muitos estão sujeitos é tanto mental (frequentemente traumatizados por torturas ou testemunho direto de assassinatos de familiares e amigos) como social. Trata-se de um sofrimento originado pelos traumas que viveram no passado, mas também pela angústia face a um presente do qual desconhecem os contornos sociais e culturais. Configura-se assim aquilo que anteriormente referimos como "violência estrutural" (Farmer 2004; Das e Kleinman 2000) e que tanto pode ocorrer repentinamente, no caso de um conflito armado, como paulatinamente, quando indivíduos ou comunidades são alvo de discriminação sistemática já no país de asilo que prometeu protegê-los. Isto acontece de cada vez que não thes são disponibilizados meios de mediação linguística e cultural para interagir com as mais variadas instituições, sempre que lhes é recusado um emprego que lhes permita a integração ou, de um modo mais pragmático, sempre que não lhes são dados os meios necessários para alugarem uma casa ou um quarto que lhes sirva de abrigo.

Na perspetiva da antropologia médica crítica, a investigação destas temáticas (minorias, imigrantes, refugiados) a partir da observação etnográfica ajuda a colocar os sujeitos como eventuais agentes políticos, construtores de uma epistemologia própria, e não apenas como um "conceito". Deste modo, os discursos jurídicos e sociais mais complexos e múltiplos necessitam de ser desconstruídos à luz das ciências sociais. Podemos afirmar que estamos no plano das normatividades fragmentadas, inerentes aos processos político-jurídico-sociais existentes no contexto de cada Estado, e na relação entre Estados. Seguindo Habermas (1997), que levantou a questão da necessidade de relação entre direito e ciências sociais na obra Direito e Democracia, diremos que são as normatividades produzidas no campo jurídico que começam agora, particularmente em Portugal, a ser questionadas pela investigação académica nas ciências sociais e humanas, mas também, e com maior precisão, pelo ativismo militante de organizações sociais de base. Por um lado, refere-se a necessidade de reconhecer e legitimar a narrativa dos indivíduos que, até há bem pouco tempo, eram (e em alguns casos, continuam a ser) marginais ao sistema e que falam a partir das suas experiências e carências quotidianas. Por outro lado, existe a imperatividade dos princípios legais que permite, ou proíbe, a sua integração no Estado-nação reconhecendo-lhes, ou não, o papel de cidadãos de pleno direito. Coloca-se, assim, a pertinência de dar sentido ao social através da observação das práticas do quotidiano, destacando as contradições entre o 
sistema jurídico e as dificuldades da vida do dia a dia. As normatividades jurídicas, nomeadamente as que regem o acesso destes indivíduos à habitação ou à saúde, por exemplo, carecem de maior flexibilidade e abertura à subjetividade inerente à multiplicidade de perspetivas individuais, culturais, mas, sobretudo, sociais e políticas.

No espetro do asilo em Portugal, a maioria dos refugiados é também vítima da já referida "violência estrutural" (Farmer 2004), no sentido em que é sistematicamente condicionada por um sistema político, económico e institucional - onde se podem incluir instituições filantrópicas de assistencialismo social. Ao pretenderem "fazer o bem" através da ação social, estas instituições extrapolam frequentemente as suas funções, acabando por controlar a vida quotidiana, em particular dos requerentes de asilo. Através da coação direta ou velada, causam-lhes mais danos, uma vez que não estão preparadas para, junto deles, encontrarem soluções para o seu sofrimento. Ao negarem reconhecê-los como agentes ativos de mudança - ou seja, ao não reconhecerem a sua agencialidade -, retiram-lhes o direito a fazerem uso efetivo das instituições que, não estando suficientemente preparadas para integrar a diferença, acabam por remetê-los para um silêncio sofredor, condicionando-os sistematicamente a um de dois papéis: o de vítimas das violências passadas que os tornaram impotentes e passivos, ou o de oportunistas que pretendem usufruir abusivamente de um sistema de proteção social.

A vitimização dos refugiados é também, portanto, "um produto da intervenção humanitária, em particular no assistencialismo social”, tal como afirmam Pussetti e Brazzabeni (2011: 471). Nega-se-lhes o reconhecimento da capacidade de resiliência, negam-se-lhes os conhecimentos e até as capacidades pessoais e profissionais que possuíam nos seus países de origem e, portanto, a capacidade para intervirem ativamente na sociedade, silenciando-lhes as vidas, as narrativas de sofrimento e os discursos de reivindicação social. Em suma, e como escreve Agamben (1997), os indivíduos em sofrimento são reduzidos à "vida nua". Como contraponto, ao menor sinal de tentativa de organização coletiva com vista à representatividade e reivindicação em face de tratamentos abusivos por parte de alguns inspetores no local de atendimento a refugiados no SEF, os requerentes de asilo são ameaçados de expulsão, por alegadamente colocarem em causa a segurança pública. Tal aconteceu em 2010, quando um pequeno grupo de refugiados decidiu apresentar-se coletivamente no serviço de atendimento do SEF, exigindo explicações plausíveis para o atraso sistemático com que eram tratados os seus documentos e que os impedia de trabalhar. Após ter sido exigido a cada um o preenchimento de uma lista com nome, contacto e assinatura numa folha com um texto escrito em português - algo intimidante, uma vez que a maioria não sabia o que estava a assinar por não entender o português -, foi identificado o mentor da reivindicação para, de seguida, lhe ser entregue um documento que o 
impelia a sair do país num prazo de trinta dias. Esta ameaça acabou por não ser cumprida, uma vez que foi alertado o Conselho Português para os Refugiados, que se supõe ter tido um papel interveniente a favor do requerente, evitando-se por isso a aplicação desta medida drástica. Este facto leva-nos a considerar que os refugiados são vistos pelas instituições de assistencialismo e controlo como uma categoria social sem liberdade para usufruir dos seus direitos de cidadania, relegada para uma existência anónima e apolítica, fortemente dependente de decisões alheias que determinarão o seu percurso na sociedade de asilo. ${ }^{28}$

\section{O CARÁTER POLÍTICO DA ESPERA}

Fassin e Rechtman usam o termo "governamentalidade". Para eles, este conceito aplica-se a

“[...] instituições, procedimentos, ações e reflexões que têm a população como objeto, que extravasam a questão da soberania e complicam a questão do controlo, que relacionam o poder e a administração do Estado com a subjugação e subjetivação dos indivíduos, que assentam na economia política e no policiamento tecnológico" (2009: 214).

A limitação da capacidade de ação dos sujeitos refugiados à entrada do país de asilo e já em contexto de proteção é também marcada pela "espera". A espera adquire um caráter político e dela são vítimas todas as populações que dependem economicamente das ajudas dos sistemas estatais. No caso dos requerentes de asilo, a espera começa na avaliação do pedido nos centros de retenção de fronteira, como nos aeroportos, por exemplo, podendo tardar várias semanas, mesmo quando se trata de menores não acompanhados e ao contrário do que está previsto na lei. Prolonga-se depois pelos meses em que estão institucionalizados no Centro de Acolhimento para Refugiados e onde esperam sistematicamente pelo atendimento das assistentes sociais, pela consulta no centro de saúde, ou pelo emprego vagamente prometido que idealmente lhes iria permitir sair da dependência dos sistemas assistencialistas. Carolina Kobelinsky (2010), no livro L'accueil des demandeurs d'asile, chama a atenção para o caráter político da espera imposta aos requerentes de asilo:

28 Recentemente assisti a um outro episódio, passado na Segurança Social. O refugiado que eu acompanhava informou a assistente social responsável pelo seu dossiê de que se iria ausentar do país por uma semana. Esta iniciou um longo interrogatório sobre as razões desta ida ao estrangeiro e de onde vinha o financiamento para a viagem, alegando que não compreendia como um refugiado tinha dinheiro para viajar, quando ela própria, sendo portuguesa e profissional ativa, não tinha dinheiro para fazer as viagens que gostaria de fazer. 
"A espera constitui uma espécie de grelha de leitura a partir da qual se torna possível examinar o tratamento quotidiano dos requerentes de asilo. [...] Por política da espera entendo igualmente a relação estreita entre a experiência da espera e o exercício do poder" (2010:22).

A obrigação da espera pode também ser interpretada como uma forma de imposição de submissão. O tédio que ela provoca, numa perspetiva de saúde mental, acaba por ser prenúncio de conflitos individuais e coletivos, intensificados por um forte sentimento de inutilidade. ${ }^{29}$ Todos os refugiados com quem trabalhei eram unânimes em afirmar o seu desespero pela condição a que eram submetidos. Os primeiros dias passados no centro de acolhimento eram encarados com alguma sensação de alívio em relação ao que tinham vivido até ali. Mas este alívio era vivido sem plenitude, uma vez que sabiam que, após a saída obrigatória desse lugar, tudo poderia tornar-se mais difícil, pela ausência de apoios permanentes por parte do CPR. O futuro configurava-se, pois, como uma enorme incógnita. O centro, apesar de ser reconhecido pela maioria como um "abrigo", não deixava de ser um lugar de incertezas e dependências, uma fronteira simbólica e espacial em relação à sociedade portuguesa, um lugar entre parêntesis num contínuo de fuga e luta por um reconhecimento na sociedade de asilo, onde apenas a agencialidade poderá dar lugar a caminhos autónomos e dignificantes longe do sofrimento social. Segundo os autores Kleinman, Das e Lock (1997), o sofrimento não pode ser entendido de modo independente das dinâmicas sociais e dos interesses políticos e económicos que o originam. É necessário, portanto, um olhar crítico sobre as relações de poder que originam este sofrimento, e este deve assentar na análise das experiências de vida e das narrativas dos sujeitos vitimizados pelas políticas sociais.

\section{UMA MUDANÇA DE PARADIGMA}

Liisa Malkki (1995) refere que a vitimização dos refugiados é um produto da intervenção humanitária. Uma das consequências da vitimização entre os refugiados hutu da Tanzânia, estudados por esta autora, é também a despolitização da categoria de refugiado, despersonalizando as especificidades por detrás de cada pessoa, associando-lhes o papel generalizado de vítimas sem

29 Nos meses em que permanecem no Centro de Acolhimento para Refugiados (CAR), a televisão permanentemente ligada e os contactos virtuais através do telemóvel são a principal distração dos que aí residem, para além de alguma aprendizagem de português promovida pelo próprio CPR. Com exceção de alguns passeios pontuais (organizados pelo CPR) e que pretendem dar a conhecer Portugal aos residentes do CAR, poucas atividades lúdicas existem. O desconhecimento generalizado da geografia e da sociedade onde estão agora inseridos e o medo de se perderem num lugar desconhecido sem dominarem a língua nem a cultura fá-los permanecer passivamente no CAR, sem outras atividades para além das descritas. 
voz. De acordo com Malkki, as práticas humanitárias tendem a passar por cima das vozes dos refugiados, e as imagens difundidas pelos meios de comunicação ou pelas campanhas humanitárias, em particular nos campos de refugiados, são igualmente responsáveis pelo silenciamento das suas vozes e dos seus discursos.

Uma das propostas de Turton (2003) e Bauman (1998) é a de focar a abordagem destes migrantes não necessariamente nas suas experiências e necessidades - como "maioria pobre que está preparada para correr riscos tremendos de modo a escapar ao 'desconforto da existência localizada'” (Bauman 1998: 2) -, mas, pelo contrário, em nós próprios. Na conceção apresentada por este autor, os "migrantes forçados" - refugiados e requerentes de asilo -, ao contrário dos imigrantes, esperam algo de nós. Solicitam-nos cidadania, solicitam-nos proteção por razões humanitárias, solicitam-nos asilo (mesmo sem que tal seja entendido pelos próprios como algo que corresponda a uma categorização jurídica), num contexto que se autodefine como sociedade democrática e liberal e, para mais, defensora dos direitos humanos. Ou seja, levam-nos a confrontar-nos com as nossas próprias assunções ideológicas, morais e éticas e com as correspondentes responsabilidades que retoricamente assumimos quando enfrentamos pessoas estrangeiras em situação de aflição e sofrimento: "Por outras palavras, eles levam-nos a questionar quem somos - o que é ou deve ser a nossa comunidade moral e, em última instância, o que significa ser humano" (Turton 2003: 8).

Em conclusão, diremos que se afigura como necessária e urgente uma mudança de paradigma nas políticas públicas e na sociedade como um todo. Em lugar de se olhar para os refugiados exclusivamente do ponto de vista da vitimização, do assistencialismo ou até do logro, é necessário garantir-lhes o direito ao reconhecimento enquanto cidadãos, através do seu próprio envolvimento político e relacional. Não existe uma verdadeira relação com as estruturas políticas e sociais que juridicamente estão incumbidas de dar apoio aos refugiados ou, mesmo quando existe, os procedimentos burocráticos empurram-nos frequentemente para situações liminares próximas da ilegalidade. O reconhecimento da sua voz ativa e a necessidade do seu envolvimento nas ações de integração são o meio mais eficaz para a realização de uma vida digna onde se respeitem na realidade - e não só na lei - os direitos humanos. É necessário criar sociedades baseadas na escuta, no diálogo e no respeito pelos direitos dos cidadãos - ou seja, sociedades plurais onde os imigrantes, refugiados e autóctones criem laços e trocas reais e simbólicas, produtivas para todos, sem recurso a manipulações de acordo com os interesses políticos ou económicos dos Estados-nação. E isso implica a transformação profunda das instituições e da nossa relação com elas. 


\section{BIBLIOGRAFIA}

ACNUR, 2007 [1951], Convenção Relativa ao Estatuto dos Refugiados, Genebra, UNHCR <http://www.fd.uc.pt/CI/CEE/pm/Tratados/Amesterdao/conv-genebra-1951.htm>.

AGAMBEN, Giorgio, 1997, Homo sacer I: Le pouvoir souverain et la vie nue. Paris, Seuil.

AGIER, Michel, 2008, Gérer les indésirables: Des camps de réfugiés au gouvernement humanitaire. Paris, Flammarion.

ARENDT, Hannah, 1978 [1943], "We refugees", em Hannah Arendt, The Jew as Pariah: Jewish Identity and Politics in the Modern Age, org. e introd. de Ron H. Feldman. Nova Iorque, Grove Press, 55-66.

BAliBar, Etienne, 1994, Masses, Classes, Ideas: Studies on Politics and Philosophy Before and After Marx. Nova Iorque e Londres, Routledge.

BAUMAN, Zygmunt, 1998, Globalization: The Human Consequences. Cambridge, Polity Press. BAUMAN, Zygmunt, 2005, Liquid Life. Cambridge, Polity Press.

BAUMAN, Zygmunt, 2006, Europa: Uma Aventura Inacabada. Rio de Janeiro, Jorge Zahar Editor.

DAS, Veena, e Arthur KLEINMAN, 2000, “Introduction”, em Veena Das et al. (orgs.), Violence and Subjectivity. Berkeley, Los Angeles e Londres, University of California Press, 1-18.

FARMER, Paul, 2004, "An anthropology of structural violence: Sidney W. Mintz lecture for 2001 ", Current Anthropology, 45 (3): 305-325.

FARMER, Paul, 2005, Pathologies of Power: Health, Human Rights, and the New War on the Poor, pref. de Amartya Sen. Berkeley, Los Angeles e Londres, University of California Press.

FARMer, Paul, 2010, Partner to the Poor: A Paul Farmer Reader, org. Haun Saussy. Berkeley, Los Angeles e Londres, University of California Press.

FASSIN, Didier, 2005, "Compassion and repression: the moral economy of immigration policies in France”, Cultural Anthropology, 20 (3): 362-387.

FASSIN, Didier, 2011, "Policing borders, producing boundaries: the governmentality of immigration in dark times", Annual Review of Anthropology, 40: 213-226.

FASSIN, Didier, e Richard RECHTMAN, 2009, The Empire of Trauma: An Inquiry into the Condition of Victimhood. Princeton, NJ, Princeton University Press (tradução de Rachel Gomme).

GREEN, D., 1999, Gender Violence in Africa: African Women's Responses. Nova Iorque, St. Martin's Press.

HABERMAS, Jürgen, 1997, Direito e Democracia: Entre Facticidade e Validade, 2 vols. Rio de Janeiro, Tempo Brasileiro.

KLEINMAN, Arthur, Veena DAS, e Margaret LOCK (orgs.), 1997, Social Suffering. Berkeley, University of California Press.

KOBELINSKY, Carolina, 2010, L'accueil des demandeurs d'asile: Une ethnographie de l'attente. Paris, Éditions du Cygne.

LÉVI-STRAUSS, Claude, 1992, The View from Afar. Chicago, The University of Chicago Press.

MALKKI, Liisa H., 1995, "Refugees and exile: from 'refugees studies' to the national order of things", Annual Review of Anthropology, 24: 495-523.

MESSER, Ellen, 1993, "Anthropology and human rights", Annual Review of Anthropology, 22: 221-249. 
PUSSETTI, Chiara, e Micol BRAZZABENI, 2011 , "Sofrimento social: idiomas da exclusão e políticas do assistencialismo”, Etnográfica, 15 (3): 467-478.

SÁNCHEZ RUBIO, David, 2007, Contra Una Cultura Anestesiada de Derechos Humanos. San Luis Potosi (México), Facultad de Derecho de la Universidad Autónoma de San Luis Potosi.

SANTINHO, Maria Cristina, 201 1, Refugiados e Requerentes de Asilo em Portugal: Contornos Políticos no Campo da Saúde. Lisboa, ISCTE-IUL, tese de doutoramento, <http://hdl.handle. net/10071/3512>.

SASSEN, Saskia, 1999, Guests and Aliens. Nova Iorque, The New Press.

SCHEPER-HUGHES, Nancy, 1995, "The primacy of the ethical: propositions for a militant anthropology”, Current Anthropology, 36 (3): 409-420.

SCHEPER-HUGHES, Nancy, 1996, "The madness of everyday life: in search of a critical and engaged anthropology", Ethnostoria, n.s., 1-2: 35-51.

SCHEPER-HUGHES, Nancy, e Margaret LOCK, 1987, "The mindful body: a prolegomenon to future work in medical anthropology”, Medical Anthropology Quarterly, 1 (1): 6-41.

SEF, 2001, Em Direç̧̃ã a Um Sistema Comum Europeu de Asilo: Conferência Europeia sobre Asilo, atas da conferência de 15 e 16 de junho de 2000, Serviço de Estrangeiros e Fronteiras, Gabinete de Documentação e Direito Comparado, Procuradoria-Geral da República, $<$ http://www.sef.pt/documentos/56/actas-coferencia\%20portugues 1.pdf >.

SEF, 2006, Relatório de Actividades 2006: Imigração, Fronteiras e Asilo, Lisboa, Serviço de Estrangeiros e Fronteiras, <http://sefstat.sef.pt/Docs/Rifa_2006.pdf>.

SOGUK, Nevzat, 1999, States and Strangers: Refugees and Displacements of Statecraft. Minneapolis, University of Minnesota Press.

TURTON, David, 2003, “Conceptualising forced migration”. Oxford, Refugee Studies Centre, University of Oxford, RSC Working Paper, 12. 